\title{
Influence of symptoms of depression on the quality of life of men diagnosed with prostate cancer
}

\author{
Taysi Seemann' \\ Fernanda Pozzobom \\ Melissa de Carvalho Souza Vieira' \\ Leonessa Boing' \\ Zenite Machado? \\ Adriana Coutinho de Azevedo Guimarães'
}

Abstract

Objective: to evaluate the prevalence of symptoms of depression among men diagnosed with prostate cancer and their association with quality of life and treatment-related factors. Methods: a cross-sectional study of 85 men with a mean age of $66 \pm 8$ years who were diagnosed with prostate cancer was performed. The survey was based on a questionnaire with previously validated instruments which investigated social, demographic and economic characteristics, the history of the disease, quality of life (European Organization for Research and Treatment of Cancer Questionnaire C30 - EORTC QLQ-C30 / QLQ-PR25) and symptoms of depression (Beck Depression Inventory). The presence of symptoms of depression was considered an outcome, and statistical analyzes were performed using the Chi-square test, Fisher's exact test, Mann Whitney U test and Poisson regression $(p<0.05)$. Results: significant results were found for quality of life in

Keywords: Prostate Neoplasm. Quality of Life. Depression Symptoms. relation to symptoms of depression in the functional, global and symptomatic health scale $(p<0.001)$. This demonstrates that the presence of symptoms of depression is related to a negative quality of life. Conclusions: for a greater understanding of prostate cancer and its consequences on the quality of life of patients it is important to consider possible disorders in psychological aspects caused by the illness, as symptoms of depression are frequent in patients undergoing treatment for prostate cancer.

Universidade do Estado de Santa Catarina, Programa de Pós-graduação em Ciência do Movimento Humano. Florianópolis, SC, Brasil. 


\section{INTRODUCTION}

With increased prevalence since the 1960s, prostate cancer is considered a global public health problem. It is the sixth most common cancer in the world and accounts for about $10 \%$ of all such diseases ${ }^{2}$. In Brazil, it is the second most common type of cancer among men and it is estimated that of the 600,000 new cancer cases in 2016 and 2017, 61,000 thousand involve prostate cancer ${ }^{3}$. The Brazilian Society of Urology ${ }^{4}$ observes that Santa Catarina is one of the Brazilian states with the highest incidence of cases.

The increase in this incidence over the years can be explained by the evolution of diagnostic methods and the improvement of the quality of the country's information systems ${ }^{5}$. Faced with such increased incidence, early diagnosis and appropriate treatment are essential, along with suitable posttreatment and the individual's perception of their quality of $l i f e^{6}$, as all the therapeutic modalities present significant risks and side effects to patients ${ }^{5}$.

Among the modalities of treatment for prostate cancer, radical prostatectomy, in which the patient undergoes complete removal of the prostate, is the oldest and possibly the most effective ${ }^{7}$. Such a method can cause several side effects, such as urethral stenosis, urinary incontinence, erectile dysfunction ${ }^{5}$, fatigue, general distress, functional disability and depression ${ }^{8,9}$, factors that can significantly affect the quality of life of such men ${ }^{5}$.

Studies evaluating quality of life and prostate cancer have identified depression as one of the main psychological problems exhibited ${ }^{10-12}$, and this condition is present in one in five patients ${ }^{13}$. Depression can trigger problems related to recovery and a decrease in immunity, minimizing the survival chances of patients ${ }^{14}$, and the treatment of cancer through adjuvant chemotherapy may further increase the risk of this condition ${ }^{15}$. Patients live with pain, physical disfigurement and the threat of death on a daily basis, and these problems often do not end with surgery or the completion of conventional treatment, as the phantoms of metastasis and the recurrence of the disease remain, leading to states of depression and negative quality of life ${ }^{13}$.

Surveys that address the relationship between depressive symptoms and the quality of life of patients with prostate cancer are extremely important, as greater knowledge about the subject may aid in the treatment and post-treatment of the disease, as well as the promotion of the good social and mental wellbeing of these patients, which are essential to their daily life. The objective of the present study was therefore to evaluate the prevalence of depressive symptoms in men diagnosed with prostate cancer and the association with quality of life scores and factors related to treatment.

\section{METHODS}

An observational, analytic cross-sectional study was performed, comprised of 85 men diagnosed with prostate cancer undergoing treatment and posttreatment in the Centro de Pesquisas Oncológicas (the Center of Oncological Research) (CEPON) in the city of Florianópolis, Santa Catarina, Brazil. The recruitment of these men occurred in various sectors of CEPON, namely the chemotherapy, radiotherapy and physiotherapy centers and the waiting rooms of doctors' surgeries. Their selection was based on inclusion criteria, namely that they were between 40 and 80 years and were in the clinical treatment or post-treatment phase. The exclusion criteria included a classification of illiterate in level of schooling due to the need to understand the questionnaire, previous oncological treatment in an institution other than CEPON, or a diagnosis of metastasis, to avoid bias in the type of treatment and prognosis. The sample size was calculated based on a significance level of $5 \%$, a test power of $80 \%$ and a mean effect size of 0.5 considering the comparison of means test, meaning that 102 patients were required to compose the sample.

The data were collected using a structured questionnaire, applied by three researchers trained for this task. All patients who agreed to voluntarily participate in the study were asked to sign a Free and Informed Consent Form.

The structured questionnaire included variables relating to the general characterization of the sample, anthropometric measurements (body mass and height), symptoms of depression and quality of life. General characteristics and those related to disease (age, marital status, education, economic level, presence of diseases, surgical intervention), as well as the anthropometric measures were self-reported. 
The classification of weight was performed based on the calculation of Body Mass Index (BMI), and was categorized according to the $\mathrm{WHO}^{16}$, which suggests: underweight $(\mathrm{BMI}<18.4)$; normal weight (BMI 18.5-24.9); overweight (BMI 25.0-29.9); preobesity and obesity (BMI>30.0). For the present study, for statistical purposes, we chose to group the categories into normal weight (underweight and normal weight) and overweight (overweight, pre-obesity and obesity) due to the low numbers in those categories.

Economic level was verified based on the IBGE criterion, classifying the subjects into economic strata $\mathrm{A}, \mathrm{B}, \mathrm{C}, \mathrm{D}$ and $\mathrm{E}$, according to number of minimum wages in the monthly family income, based on the 2014 minimum wage of $\mathrm{R} \$ 724.00$. Due to the lower number of men in these categories, the subjects were classified into upper class $(\mathrm{A}+\mathrm{B})$, middle class $(\mathrm{C})$, and lower class $(\mathrm{D}+\mathrm{E})$.

Quality of life was evaluated through the European Organization for Research and Treatment of Cancer Questionnaire C30 - EORTC QLQ-C30 ${ }^{17}$, validated in Brazil with a Cronbach alpha score of 0.72 for the overall health scale, 0.86 for the functional scale and 0.81 for the symptomatic scale ${ }^{1,18}$. This questionnaire is based on assessing the quality of life of cancer patients over the last four weeks, in terms of functional (physical, functional, emotional, social and cognitive), symptomatic (fatigue, pain and nausea/ vomiting, dyspnea, insomnia, appetite, constipation, diarrhea and financial difficulties) and global health. The question scores result in a total score from 0 to 100 , with the higher the value found the better the quality of life in the overall and functional scales. In the symptomatic scale, meanwhile, a higher value represents a greater presence of symptoms, determining a worse quality of life. The EORTC QLQ-C30 is supplemented by specific modules for different types of cancer, and the QLQ-PR25 is specifically used for prostate cancer. This instrument has 25 questions incorporated in multi-item scales to measure the symptoms of the treatment over the previous week, the symptoms occurring in the last four weeks and sexual functioning.

The Beck Depression Inventory (BDI), originally developed by $\mathrm{Beck}^{19}$, was used to investigate depressive symptoms. It is a self-reported instrument with 21 multiple-choice objective questions that indicate depressive symptoms (lack of hope, irritation, depressive cognitions, guilt and feelings of punishment, as well as physical symptoms such as fatigue, weight loss and loss of sexual interest). It was validated in Brazil by Cunha ${ }^{20}$, who maintained the original scale of 21 items, with scores ranging from zero to three, with four alternative responses, which correspond to increasing levels of the severity of depression. The BDI has been successfully used in studies with men with cancer ${ }^{21,22}$. The scores of the individual items are added together and result in a total score, with a maximum score of 63 points, which indicates a high degree of depression, and a lowest possible score of zero, which corresponds to the absence of depression. Categorization was performed according to the standardization used in studies with cancer patients, with scores from zero to 10 equaling without depression or minimal depression; scores from 11 to 18 representing mild depression; scores from 19 to 29 corresponding to moderate depression; and scores from 30 to 63 indicating severe depression ${ }^{23}$. For statistical and analytical reasons, scores were categorized into the absence of depressive symptoms (scores from zero to 10) and the presence of depressive symptoms (scores $\geq 11$. We chose not to use the term depression, as this term is only recommended for use in patients with concomitant clinical diagnosis ${ }^{24}$.

In order to compare general characteristics and those related to disease and quality of life among the groups with the presence and absence of depressive symptoms, the chi-squared test or Fisher's exact test were used. The Mann Whitney U-Test was used to compare the quality of life scores of the groups, as the Kolmogorov Smirnov Test ( $\mathrm{p}>0.05)$ did not identify the data as normal, except for the functional scale variable. Poisson regression was used to estimate the crude and adjusted prevalence ratios (PR) with a respective 95\% CI. The dependent variable (outcome) was the presence of depressive symptoms, so for regression analysis the sample was divided into two groups, namely men with depressive symptoms and those without depressive symptoms. Adjusted analysis was performed for all the demographic, social, economic and clinical variables. The criterion for remaining in the adjusted analysis was a value of $p \leq 0.20$. 
The data were collected between October 2014 and July 2015. The study complied with National Health Council Resolution n ${ }^{\circ}$ 466/2012 and was approved by the Ethics Committee on Research Involving Human Beings (CEPSH) of UDESC, protocol $n^{\circ} 688.548$ on June 16, 2014 and by the Ethics Research Committee of CEPON (CEP), protocol no 818.174, on October 3, 2014.

\section{RESULTS}

Although there were no significant differences in the variables, it was observed that the men with depressive symptoms were mostly older (61 to 80 years $(76.9 \%))$, had attended elementary school $(53.8 \%)$, were unemployed, retired or absent from work due to health reasons $(84.6 \%)$, of a lower economic class $(88.5 \%)$, married $(80.8 \%)$ and overweight $(61.5 \%)$. These data are not shown in the table.
Table 1 presents the data comparing the groups with the absence and presence of depressive symptoms in relation to the demographic, social and economic characteristics of the study participants.

The clinical characterization of the participants revealed that $64.7 \%$ of the patients had other diseases, $48.2 \%$ reported urinary incontinence, $54.1 \%$ had not undergone radical prostatectomy surgery as a form of treatment, while the majority $(56.8 \% \%)$ underwent radiotherapy and did not finish treatment (43.5\%). In addition, $89.4 \%$ of the participants did not receive advice to undergo physiotherapy as part of the treatment (data not shown in the table).

Table 2 shows the characteristics of the disease in relation to the absence or presence of depressive symptoms. A significant result was found in the physiotherapy category $(p<0.021)$, in which men with the greatest presence of depressive symptoms were those who did not undergo such treatment $(76.9 \%)$.

Table 1. Comparison between groups with absence and presence of depressive symptoms in relation to the demographic, social and economic characteristics of men after the diagnosis of prostate cancer $(\mathrm{N}=85)$. Florianópolis, Santa Catarina - CEPON 2014/2015.

\begin{tabular}{|c|c|c|c|c|}
\hline \multirow[b]{2}{*}{ Variables } & \multicolumn{4}{|c|}{ Depressive symptoms } \\
\hline & $\begin{array}{l}\text { Absent } \\
\mathrm{n}(\%)\end{array}$ & $\begin{array}{l}\text { Present } \\
\mathrm{n}(\%)\end{array}$ & $p$ value & PR $(\mathrm{CI} 95 \%)^{* * *}$ \\
\hline Age (years) & & & $0.222 *$ & \\
\hline 40 to 60 & 11(18.6) & $6(23.1)$ & & $1.061(0.825-1.364)$ \\
\hline 61 to 80 & 48(81.4) & $20(76.9)$ & & 1 \\
\hline Schooling & & & $0.315^{*}$ & \\
\hline Elementary School & $35(60.3)$ & $14(53.8)$ & & 1 \\
\hline High School or Higher Education & $23(39.7)$ & $12(46.2)$ & & $1.059(0.865-1.296)$ \\
\hline Current profession & & & $0.210^{* *}$ & \\
\hline Unemployed/Retired/Sick Leave & $43(72.9)$ & $22(84.6)$ & & $1.149(0.931-1.416)$ \\
\hline Up to two categories & $16(27.1)$ & $4(15.4)$ & & 1 \\
\hline Marital status & & & $0.307^{*}$ & \\
\hline Partner & $41(69.5)$ & $21(80.8)$ & & $1.129(0.919-1.387)$ \\
\hline No partner & $18(30.5)$ & $5(19.2)$ & & 1 \\
\hline Economic class & & & $0.769 * *$ & \\
\hline Upper Class (A+B) & $2(3.4)$ & $1(3.8)$ & & $1.158(0.899-1.492)$ \\
\hline Middle Class (C) & $9(15.5)$ & $2(7.7)$ & & 1 \\
\hline Lower Class (D+E) & $47(81.0)$ & $23(88.5)$ & & $1.164(0.651-2.078)$ \\
\hline Weight status & & & $0.689 *$ & \\
\hline Overweight & $41(70.7)$ & 16(61.5) & & 1 \\
\hline Normal weight & $17(29.3)$ & $10(38.5)$ & & $1.094(0.881-1.358)$ \\
\hline
\end{tabular}

*Chi-squared test; **Fisher's Exact Test; ***Prevalence Ratio - Poisson's Regression. 
Table 2. Comparison between groups with the absence and presence of depressive symptoms in relation to the characteristics of the disease and the treatment of men after the diagnosis of prostate cancer $(\mathrm{N}=85)$. Florianópolis, Santa Catarina - CEPON 2014/2015.

\begin{tabular}{|c|c|c|c|c|}
\hline \multirow[b]{2}{*}{ Variables } & \multicolumn{3}{|c|}{ Depressive symptoms } & \multirow[b]{2}{*}{ PR $(\mathrm{CI} 95 \%)^{* * *}$} \\
\hline & $\begin{array}{l}\text { Absent } \\
\mathrm{n}(\%)\end{array}$ & $\begin{array}{l}\text { Present } \\
\mathrm{n}(\%)\end{array}$ & $p$ value & \\
\hline Suffers other diseases & & & $0.562 *$ & \\
\hline Yes & $37(62.6)$ & 18(69.2) & & $1.062(0.869-1.299)$ \\
\hline No & $22(37.3)$ & $8(30.8)$ & & 1 \\
\hline Urinary incontinence & & & $0.247 *$ & \\
\hline Yes & $15(44.1)$ & $26(57.7)$ & & $1.123(0.924-1.365)$ \\
\hline No & $11(55.9)$ & $33(42.3)$ & & 1 \\
\hline Radical prostatectomy & & & $0.973 *$ & \\
\hline Did not undergo & $14(54.2)$ & $32(53.8)$ & & 1 \\
\hline Underwent & $12(45.8)$ & $27(46.2)$ & & $1.003(0.824-1.221)$ \\
\hline Type of treatment & & & $0.528^{* *}$ & \\
\hline Chemotherapy & $5(21.7)$ & $2(14.3)$ & & 1 \\
\hline Radiotherapy & $14(60.9)$ & $7(50.0)$ & & $1.049(0.710-1.55)$ \\
\hline Hormone therapy & $4(17.4)$ & $5(35.7)$ & & $1.310(0.822-2.088)$ \\
\hline Finished o treatment & & & $0.154 *$ & \\
\hline Yes & $12(20.3)$ & $7(26.9)$ & & $1.217(0.941-1.573)$ \\
\hline No & $23(39.0)$ & $14(53.8)$ & & $1.229(0.998-1.513)$ \\
\hline Not yet started & $24(40.7)$ & $5(19.2)$ & & 1 \\
\hline Physiotherapy & & & $0.021 *$ & \\
\hline Yes & $3(5.1)$ & $6(23.1)$ & & $1.497(1.083-2.069)$ \\
\hline No & $56(94.9)$ & $20(76.9)$ & & 1.00 \\
\hline
\end{tabular}

*Chi-squared test (N=85);**Fisher's exact test; ***Prevalence ratio - Poisson Regression.

In the EORTC QLQ C30 instrument, the closeness of the score to 100 represented a better quality of life; except on the symptomatic scale where a score closer to 100 meant a worse quality of life. The results of the comparison between quality of life and the absence and presence of depressive symptoms are presented in Table 3. Significant results were observed in most variables, except for loss of appetite ( $p=0.078)$ and sexual functioning $(p=0.068)$.

In the components of the functional scale, men with depressive symptoms had a more negative quality of life than those with the absence of depressive symptoms, with $p<0.001$ for the emotional, physical and social functions, and $p=0.025$ for cognitive function. The same was found in the overall health scale $(p<0.001)$. In the symptomatic scale, significant differences were observed for the majority of variables, namely fatigue $(p<0.001)$, insomnia $(p<0.003)$, pain $(p<0.003)$, nausea and vomiting $(p<0.011)$, dyspnea $(p<0.041)$ diarrhea $(p<0.050)$ and financial difficulties $(p<0.011)$, but not for the variable loss of appetite. Worse results were found among men with depressive symptoms.

When the specific instrument for men with prostate cancer (EORTC-PR25) was observed, significant results $(p<0.039)$ were identified on the functional scale, as well as for all the variables of the symptomatic scale, with the presence of depressive symptoms group exhibiting worse quality of life results. 
Table 3. Comparison between the groups with absence and presence of depressive symptoms in relation to the quality of life of men following the diagnosis of prostate cancer (N=85). Florianópolis, CEPON 2014/2015.

\begin{tabular}{|c|c|c|c|c|}
\hline \multirow[b]{2}{*}{ Variables } & \multirow[b]{2}{*}{$\begin{array}{l}\text { Total } \\
\text { Mean ( } \pm \text { sd) }\end{array}$} & \multicolumn{2}{|l|}{ Depressive symptoms } & \multirow[b]{2}{*}{$p$ value } \\
\hline & & $\begin{array}{l}\text { Absent } \\
\text { Mean }( \pm \text { sd })\end{array}$ & $\begin{array}{l}\text { Present } \\
\text { Mean }\left( \pm_{\text {sd }}\right)\end{array}$ & \\
\hline \multicolumn{5}{|l|}{ EORTC-C30 } \\
\hline \multirow[t]{2}{*}{ Functional scale * } & $78.77 \pm 18.48$ & $86.10 \pm 10.07$ & $62.13 \pm 22.30$ & $<0.001$ \\
\hline & Median (Q25-Q75) & Median (Q25-Q75) & Median (Q25-Q75) & \\
\hline Cognitive function & $83.33(66.66-100.00)$ & $100.00(83.88-100.00)$ & $75.00(66.66-100.00)$ & 0.025 \\
\hline Emotional function & $75.00(54.16-91.66)$ & $83.33(66.67-100.00)$ & $50.00(25.00-75.00)$ & $<0.001$ \\
\hline Physical function & $93.33(73.33-93.33)$ & $93.33(80.00-100.00)$ & $70.00(36.67-93.33)$ & $<0.001$ \\
\hline Social function & $100.00(66.66-100.00)$ & $100.00(100.00-100.00)$ & $75.00(66.66-100.00)$ & $<0.001$ \\
\hline Overall health scale** & $75.00(15.38-35.89)$ & 83.33(66.67-91.66) & $54.16(47.91-66.66)$ & $<0.001$ \\
\hline Symptomatic scale** & 23.07(15.38-35.89) & $20.51(12.85-28.20)$ & $42.30(23.07-62.17)$ & $<0.001$ \\
\hline Fatigue & $11.11(0.00-33.33)$ & $0.00(0.00-22.22)$ & 44.44(19.44-100.00) & $<0.001$ \\
\hline Loss of appetite & $0.00(0.00-0.00)$ & $0.00(0.00-0.00)$ & $0.00(0.00-33.33)$ & 0.078 \\
\hline Insomnia & $0.00(0.00-66.67)$ & $0.00(0.00-66.66)$ & $66.66(0.00-100.00)$ & 0.003 \\
\hline Ache & $0.00(0.00-33.33)$ & $0.00(0.00-16.66)$ & $25.00(0.00-66.66)$ & 0.003 \\
\hline Nausea and vomiting & $0.00(0.00-0.00)$ & $0.00(0.00-0.00)$ & $0.00(0.00-33.33)$ & 0.011 \\
\hline Dyspnea & $0.00(0.00-0.00)$ & $0.00(0.00-0.00)$ & $0.00(0.00-0.00)$ & 0.041 \\
\hline Cold & $0.00(0.00-33.33)$ & $0.00(0.00-33.33)$ & $16.66(0.00-100.00)$ & 0.014 \\
\hline Diarrhea & $0.00(0.00-0.00)$ & $0.00(0.00-0.00)$ & $0.00(0.00-33.33)$ & 0.050 \\
\hline Financial difficulties & $0.00(0.00-33.33)$ & $0.00(0.00-0.00)$ & $33.33(0.00-100.00)$ & $<0.001$ \\
\hline EORTC- PR25 & & & & $<0.001$ \\
\hline Functional scale ** & $84.21(64.91-93.85)$ & $91.22(78.94-96.49)$ & $71.05(59.64-84.21)$ & $<0.001$ \\
\hline Sexual activity & $66.66(33.33-66.66)$ & $50.00(33.33-83.33)$ & $75.00(50.00-100.00)$ & 0.039 \\
\hline Sexual functioning & $75.00(54.16-75.00)$ & $75.00(41.66-75.00)$ & $58.33(50.00-100.00)$ & 0.068 \\
\hline Symptomatic scale** & $15.78(6.14-35.08)$ & $8.77(3.5-21.05)$ & $28.94(15.78-40.35)$ & $<0.001$ \\
\hline Urinary symptoms & $25.00(12.50-50.00)$ & $20.83(4.16-37.50)$ & $43.75(21.87-57.29)$ & 0.001 \\
\hline Intestinal symptoms & $0.00(0.00-12.50)$ & $0.00(0.00-8.33)$ & $8.33(0.00-16.66)$ & 0.017 \\
\hline Hormone treatment & $11.11(0.00-30.55)$ & 11.11(16.67-38.88) & $22.22(16.66-38.88)$ & $<0.001$ \\
\hline Incontinence & $0.00(33.33-100.00)$ & $0.00(0.00-100.00)$ & $33.33(0.00-100.00)$ & 0.041 \\
\hline
\end{tabular}

\section{DISCUSSION}

Despite increases in survival rates and advances in diagnosis and treatment ${ }^{24}$, cancer is still considered a death sentence and carries with it psychological consequences, such as fear, sadness, and depression ${ }^{1}$. Literature shows that the main psychological problems presented by patients diagnosed with prostate cancer are depression and anxiety ${ }^{13,24}$. The aim of the present study was to investigate the relationship between the presence or absence of depressive symptoms and the quality of life of men in the treatment and post-treatment phase of prostate cancer.

The results showed that men with depressive symptoms had worse quality of life in the functional, overall health and symptomatic scales. These results corroborate the findings of Brazilian and nonBrazilian literature ${ }^{13,25}$. The functional quality of life scale identified an association with physical, 
functional, emotional, social and cognitive issues. These aspects were more affected in patients with depressive symptoms. It is known that depression has a substantial impact on the health of patients with chronic diseases, including cancer ${ }^{26}$, and that the presence of depressive symptoms is directly related to physical, psychological and social decline, with characteristics that impact quality of life and its functionality ${ }^{5,27}$. With a disease such as cancer these factors can be exacerbated, as the illness can bring feelings of inferiority and fear of rejection in social relationships ${ }^{28}$, as well as side effects such as a decline in physical functioning ${ }^{29,30}$. In addition, non-Brazilian studies have shown that cancer treatment coupled with psychological factors such as depression can also affect some cognitive functions, such as short- and long-term memory, attention span, concentration, and language skills ${ }^{6,31}$.

Life habits are closely related to cancer ${ }^{32}$ and influence quality of life in terms of physical and emotional health ${ }^{14}$. The results in the present study showed that patients with depressive symptoms had an inferior quality of life in the overall health scale. This may be due to the possible side effects of cancer treatment, such as reduced bone density, decreased muscle mass and strength, weight and body fat gain, and a decline in physical functioning ${ }^{29,30}$. A study of sixty patients undergoing prostate cancer treatment showed that their physical functioning was significantly reduced after treatment and that they suffered weight gain and reduced muscle mass ${ }^{6}$. Van den Bergh et al. ${ }^{33}$, in a study with patients at the end of treatment, found low scores for physical health, anxiety and quality of life in general.

It has been found that in the treatment period of the disease there are consequences for the physical health of the patient, such as fatigue, insomnia, nausea and vomiting, pain, dyspnea, constipation, diarrhea, urinary and intestinal symptoms and urinary incontinence ${ }^{8,9}$. In the present study, the symptomatic scale of both the general and specific questionnaire for men with prostate cancer revealed that worst results were related to the presence of depressive symptoms. Such results may be because most patients are still undergoing treatment and are affected by its consequences, as previously mentioned.

Other symptoms that are uncomfortable for patients are urinary incontinence and dysfunction in sexual activity ${ }^{1}$, aspects of the functional scale of the specific instrument for prostate cancer which demonstrated a significant relationship with the presence of depressive symptoms. A non-Brazilian study of four hundred and thirty-seven patients with prostate cancer found that, two years after treatment, urinary incontinence was present in $48.8 \%$ of men and sexual dysfunction in $82.8 \%{ }^{34}$. The treatment modalities for prostate cancer are the main causes for these two symptoms, which may persist even after the end of treatment ${ }^{3,35}$, and may be considered as a diminishing of their masculinity by patients, as the prostate is part of the masculine identity ${ }^{10}$. Literature reveals that the main feelings expressed by patients with prostate cancer are depression, failure, impotence in relation to the disease, fear of sexual impotence, anguish over loss of urinary control and autonomy, pain due to the loss of the capacity to have satisfactory erections and fear of being betrayed or abandoned by a sexual partner ${ }^{27,35}$.

It is important to highlight some limitations of the present study, such as the use of a questionnaire as a data collection tool, as well as the self-reporting of some data on the characteristics of the disease by patients, as the researchers did not have access to medical records; Also, as this is a cross-sectional study, it did not examine cause and effect relationships. Nor was it possible to achieve the expected sample size, with 17 participants fewer than required. Such a limitation may have occurred due to the refusal of some men to be part of the study, most probably due to the difficulties that accompany the treatment of cancer, as sample recruitment occurred in the hospital environment, and also because it deals with a topic considered a taboo for the population male as it affects a symbolic organ of masculinity. The advantages of the study, however, include its contribution to a greater knowledge of men with prostate cancer through other aspects of health, as well alerting to the risk that other factors, such as depression, can affect cancer treatment.

\section{CONCLUSIONS}

In view of these results, it can be seen that the presence of depressive symptoms significantly affects the quality of life of men with prostate cancer. There is therefore a need for greater support for the male 
population with this disease. These findings therefore support the idea that it is important to provide greater psychological attention to these patients in order to provide quality of information, psychological care,

\section{REFERENCES}

1. Zajdlewicz L, Hyde MK, Lepore SJ, Gardiner RA, Chambers SK. Health-related quality of life after the diagnosis of locally advanced or advanced prostate cancer: a longitudinal study. Cancer Nurs. 2017;40(5):412-9.

2. Bo Y, Jiansheng W. Effects of exercise on cancerrelated fatigue and quality of Life in prostate cancer patients undergoing androgen deprivation therapy: a meta-analysis of randomized clinical trials. Chin Med Sci J. 2017;32(1):13-21.

3. Instituto Nacional de Câncer. Estimativa 2016: incidência de câncer no Brasil. Rio de Janeiro: INCA; 2016.

4. Sociedade Brasileira de Urologia. Recomendações sobre o câncer de próstata. Rio de Janeiro: SBU; 2016.

5. Goulart DMM, Miranzi MAS, Goulart PEN. Qualidade de vida em pacientes submetidos à prostatectomia radical. Rev Eletr Enferm. 2014;16(3):625-34.

6. Phillips SM, Stampfer MJ, Chan JM, Giovannucci EL, Kenfield SA. Physical activity, sedentary behavior, and health-related quality of life in prostate cancer survivors in the health et professionals followup study. J Cancer Surviv. 2015;9(3):500-11.

7. Ward JF, Slezak JM, Blute ML, Bergstralh EJ, Zincke H. Radical prostatectomy for clinically advanced (cT3) prostate cancer since the advent of prostate specific antigen testing: 15 year outcome. BJU Int. 2015;95 (6):751-6.

8. Mundell NL, Daly RM, Macpherson H, Fraser SF. Cognitive decline in prostate cancer patients undergoing ADT: a potential role for exercise training. Endocr Relat Cancer. 2017;24(4):145-55.

9. Taaffe DR, Newton RU, Spry N, Joseph D, Chambers SK, Gardiner RA, et al. Effects of different exercise modalities on fatigue in prostate cancer patients undergoing androgen deprivation therapy: a year-long randomised controlled trial. Eur Urol. 2017;72(2):293-9.

10. Watson E, Shinkins B, Frith E, Neal D, Hamdy F, Walter F, et al. Symptoms, unmet needs, psychological well-being and health status in survivors of prostate cancer: implications for redesigning follow-up. BJU Int. 2016;117:10-9. the formation of support groups and other measures, as in many cases survival without good quality of life may not be the best option for the patient, causing more suffering.

11. Daniel K, Liz F, Sylvie ML, White I. Co-constructing sexual recovery after prostate cancer: a qualitative study with couples. Transl Androl Urol. 2015;4(2):131-8.

12. Parahoo K, McDonough S, McCaughan E, Noyes J, Semple C, Halstead EJ, et al. Psychosocial interventions for men with prostate cancer: a Cochrane Systematic Review. BJU Int. 2015;116(2):174-83.

13. Bourke L, Smith D, Steed L, Hooper R, Carter A, Catto J, et al. Exercise for men with prostate cancer: a systematic review and meta-analysis. Eur Urol. 2016;69(2):693-703.

14. Nikbakhsh N, Moudi S, Abbasian S, Khafri S. Prevalence of depression and anxiety among cancer patients. J Intern Med. 2014;5(3):167-70.

15. Michael A, Hoyt, Kristen M. Carpenter. Sexual self-schema and depressive symptoms after prostate cancer. Psycho-Oncol. 2015;24(4):395-401.

16. World Health Organization. Physical status: the use and interpretation of anthropometry. Geneva: WHO; 2004.

17. Aaronson NK, Ahmedzai S, Bergman B, Bullinger M, Cull A, Duez NJ, et al. The European Organisation for Research and Treatment of Cancer QLQ-C30: a quality-of-life instrument for use in international clinical trials in oncology. J Natl Cancer Inst. 1993;85:365-76.

18. Michels FAS, Latorre MRDO, Maciel MS. Validity, reliability and understanding of the EORTC-C30 and EORTC-BR23, quality of life questionnaires specific for breast cancer. Rev Bras Epidemiol. 2013;16(2):352-63.

19. Beck AT. An inventory for measuring depression. Arch Gen Psychiatr. 1961;4:561-71.

20. Cunha JA. Manual da versão em português das Escalas de Beck. São Paulo: Casa do Psicólogo; 2001.

21. Santos MIC. Qualidade de vida em pacientes portadores de câncer de próstata com metástase óssea [dissertação]. Fortaleza: Fundação Antônio Prudente e Escola Cearense de Oncologia; 2010.

22. Soares IC. Qualidade de vida de homens com cancer de próstata [dissertação]. Uberaba: Universidade Federal do Triângulo Mineiro; 2012. 
23. Gorestein C, Andrade L. Inventário de depressão de Beck: propriedades psicométricas da versão em português. Rev Psiquiatr Clín. 1998;25(5): 245-50.

24. Carlsson S, Drevin L, Loeb S, Widmark A, Lissbrant IF, Robinson D, et al. Population-based study of long-term functional outcomes after prostate cancer treatment. BJU Int. 2016;117(6B):36-45.

25. Pirl WF, Greer JA, Goode M, Smith MR. Prospective study of depression and fatigue in men with advanced prostate cancer receiving hormone therapy. Psycho-oncol 2008;17(2):148-53.

26. Dinh KT, Reznor G, Muralidhar V, Mahal BA, Nezolosky MD, Choueiri TK, et al. Association of androgen deprivation therapy with depression in localized prostate cancer. J Clin Oncol. 2016;34(16):1905-12.

27. Donovan KA, Walker LM, Wassersug RJ, Thompson LM, Robinson JW. Psychological effects of androgen-deprivation therapy on men with prostate cancer and their partners. Cancer. 2015;121(24):4286-99.

28. Sharpley CF, Christie DRH, Bitsika V, Agnew LL, Andronicos NM, McMillan ME, et al. Limitations in the inverse association between Psychological Resilience and depression in prostate cancer patients experiencing chronic physiological stress. Psycho-oncol. Epub 2017.

Received: July 24, 2017

Reviewed: October 30, 2017

Accepted: December 11, 2017
29. World Health Organization. Global recommendations on physical activity for health. Geneva: WHO; 2010. p. 23-9.

30. Magnabua MJ, Richman EL, Sosa EV, Jones LW, Simko J, Shinohara K, et al. Physical activity and prostate gene expression in men with low-risk prostate cancer. Cancer Causes Control. 2014;25(4):515-23.

31. Vashistha V, Singh B, Kaur S, Prokop LJ, Kaushik D. The Effects of Exercise on Fatigue, Quality of Life, and Psychological Function for Men with Prostate Cancer: Systematic Review and Meta-analyses. Eur Urol Focus. 2016;2(3):284-95.

32. Center MM, Jemal A, Lortet-Tieulent J, Ward E, Ferlay J, Brawley O, et al. International variation in prostate cancer incidence and mortality rates. Eur Urol. 2012;61(6):1079-92.

33. Van den Bergh RC, Essink-bot, ML, Roobol, MJ, et al. Anxiety and distress during active surveillance for early prostate cancer. Cancer. 2009;115(17):3868-78.

34. Bessaoud F, Orsini M, Iborra F, Rebillard X, Faix A, Soulier M, et al. Urinary incontinence and sexual dysfunction after treatment of localized prostate cancer: results from a population aged less than 65years old. Bull Cancer. 2016;103(10):829-40.

35. Benedict C, Traeger L, Dahn JR, Antoni M, Zhou ES, Bustillo N, et al. Sexual bother in men with advanced prostate cancer undergoing androgen deprivation therapy. J Sex Med. 2014;11(10):2571-80. 